\title{
Microfluidic fluid flow design with Arduino relay and temperature controller for processor
}

\begin{abstract}
Considering microfluidic technology, this work has been innovated to consist of monitoring, temperature control and cooling sections. The work consists of peltier a module attached to the heatsink and fan for cooling purposes. The peltier cooling is used to cool down the fluid from the water reservoir tank that will flow into the microfin CPU block. This work consists of one water reservoir tank that uses feedback system, which makes fluid will flow into the microfin (microfluidic) CPU block, and transferred back to the water reservoir tank. The temperature monitoring is monitored using the Intelligent Temperature Controller ( $\mathrm{XH}-$ W1401) located near the system. The Arduino coding controls the relay for the on/off operation of the whole system and the water pump is for the cooling section. Overall the methodology implemented and the controller system have been successfully designed, functionally operated and tested. It is found that, the system temperature without the cooling effect reaches up to $80^{\circ} \mathrm{Ci} 100^{\circ} \mathrm{C}$ while the temperature of the system with the microfluidic microfin CPU block can be reduced to $45^{\circ} \mathrm{Cï} 50^{\circ} \mathrm{C}$ degree when the processor becomes too hot.
\end{abstract}

Keyword: Microfluidic; Microfin; Temperature controller; Arduino; Cooling system 